\title{
Tarlov Cysts: clinical evaluation of an Italian cohort of patients
}

\author{
D. Marino $\cdot$ A. Federico
}

Received: 21 January 2014/ Accepted: 23 January 2014/Published online: 6 February 2014

(C) Springer-Verlag Italia 2014

Dr. Ferrante [1] properly stresses the importance of spontaneous intracranial hypotension $(\mathrm{SIH})$ as a cause of orthostatic headache as a symptom of Tarlov Cysts. We know from the literature that the most common cause of SIH is CSF leakage from a spinal meningeal diverticulum or simple dural tear, even if the origin of the CSF loss remains unknown on neuroimaging examinations [2-4]. The diagnosis of SIH is mainly based on clinical data, presenting with symptoms such as orthostatic headache, dizziness and tinnitus, which can be associated with distinctive neuroimaging findings based on compensatory venous hypervolemia such as dural enhancement, subdural fluid collections, dilatation of the dural sinuses and spinal epidural plexus [2-4].

In our population we did not have any case of SIH, neither from a clinical nor from a neuroradiological point of view. Nevertheless, this our finding does not exclude the possibility of having patients with SIH secondary to the presence of perineural cysts, as already reported in the literature [5]; for this reason, we agree with dr. Ferrante about the need to investigate the possible presence of Tarlov Cysts in patients with SIH.
We sincerely thank Dr. Ferrante for the clarification and for the great interest he has shown in our article [6].

\section{References}

1. Ferrante E (2014) Tarlov Cysts: clinical evaluation o fan Italian color of patients. Neurol Sci. doi:10.1007/s10072-013-1598-Z

2. Mokri B (2004) Low CSF pressure syndromes. Neurol Clin N Am 22:55-74

3. Riva-Amarante E, Simal P, San Millán JM, Masjuan J (2006) Spontaneous intracranial hypotension due to a broken dorsal perineural cyst. Neurologia 21:209-212

4. Fedi M, Cantello R, Shuey NH, Mitchell LA, Comi C, Monaco F, Versino M (2008) Spontaneous intracranial hypotension presenting as a reversible dorsal midbrain syndrome. J Neuroophthalmol 28:289-292

5. Riva-Amarante E, Simal P, San Millán JM, Masjuan J (2006) Spontaneous intracranial hypotension due to a broken dorsal perineural cyst. Neurologia 21(4):209-212

6. Marino D, Carluccio MA, Di Donato I, Sicurelli F, Chini E, Di Toro Mammarella L, Rossi F, Rubegni A, Federico A (2013) Tarlov Cysts: clinical evaluation of an italian cohort of patients. Neurol Sci 34(9):1679-1682
D. Marino $\cdot$ A. Federico

Department of Medicine, Surgery and Neurosciences, University of Siena, Siena, Italy

A. Federico $(\bowtie)$

Department of Medicine, Surgery and Neurosciences, University

of Siena, Viale Bracci 2, 53100 Siena, Italy

e-mail: federico@unisi.it 